\title{
Severe gastritis in guinea-pigs infected with Helicobacter pylori
}

\author{
E. STUREGÅRD, H. SJUNNESSON, B. HO*, R. WILLÉN†, P. ALELJUNG, H. C. NG* and \\ T. WADSTRÖM
}

Departments of Medical Microbiology and $\dagger$ Pathology, Lund University, Lund, Sweden and *Department of Microbiology, National University of Singapore, Singapore

\begin{abstract}
An appropriate animal model is essential to study Helicobacter pylori infection. The aim of this study was to investigate if $H$. pylori can colonise the guinea-pig stomach and whether the infection causes gastritis and a serological response similar to that observed in man. Guinea-pigs were infected either with fresh $H$. pylori isolates from human gastric biopsies or with a guinea-pig passaged strain. When the animals were killed, 3 and 7 weeks after inoculation, samples were taken for culture, histopathology and serology. H. pylori was cultured from 22 of 29 challenged animals. All culture-positive animals exhibited a specific immune response against $H$. pylori antigens in Western blotting and gastritis in histopathological examination. Antibody titres in enzyme immunoassay were elevated among animals challenged with $\boldsymbol{H}$. pylori. The inflammatory response was graded as severe in most animals and consisted of both polymorphonuclear leucocytes and lymphocytes. Erosion of the gastric epithelium was found in infected animals. These results suggest that the guinea-pig is suitable for studying $\mathrm{H}$. pyloriassociated diseases. Moreover, guinea-pigs are probably more similar to man than any other small laboratory animal as regards gastric anatomy and physiology.
\end{abstract}

\section{Introduction}

The gastric pathogen Helicobacter pylori, first isolated in 1982 from a patient with chronic active gastritis, is a causative agent in duodenal as well as gastric ulcers in man $[1,2]$. There is a close association between chronic $H$. pylori-induced type $\mathrm{B}$ gastritis and gastric cancer $[3,4]$. The discovery of a key bacterial pathogenic factor for these diseases dramatically changed the strategies for the treatment of peptic ulcer disease and stimulated the development of new therapies and prophylactic methods. Promising results with vaccine candidates have been demonstrated in mice, but it remains to be seen whether these data are applicable to man [5]. To develop a highly efficient vaccine and other prophylactic and therapeutic methods, appropriate animal models to mimic $H$. pyloriinduced disorders in man are essential. Earlier studies have shown that $H$. pylori can infect gnotobiotic and barrier-born pigs and monkeys, gnotobiotic dogs and nude mice [6-10]. However, some of these animals seem less appropriate for use as models of human

Received 17 Nov. 1997; revised version accepted 9 April 1998.

Corresponding author: Professor T. Wadström. disease. Furthermore, testing vaccines and therapies in some of these models could be too costly. The difficulties encountered in infecting animals with $H$. pylori have initiated the use of related Helicobacter spp. isolated from animals, such as $H$. felis from cats and $H$. mustelae from ferrets, in various animal models $[11,12]$. However, in the last 2 years new models for studying $H$. pylori-induced type B gastritis have been developed in euthymic mice and rats, and Mongolian gerbils [5, 13-17].

Man has a simple stomach with a glandular epithelium throughout and indigenous microflora is either very limited or absent. Thus an animal with a similar stomach architecture would be preferable as an experimental model. Rats, mice, rabbits, gerbils and guinea-pigs all have a simple stomach, whereas hamsters have a complex stomach, probably less suitable as a model of $H$. pylori infection. The guinea-pig is the only species among common small laboratory animals with a stomach entirely lined with a glandular epithelium and it is the only commonly used laboratory animal (apart from primates) that requires a dietary source of vitamin $C$ [18-21]. Furthermore, guinea-pigs and rabbits, but not mice and rats, express interleukin-8, important for the 
mucosal inflammatory response [22]. This study describes a guinea-pig model for studying $H$. pyloriinduced gastric disorders; this was presented earlier as a poster [23].

\section{Materials and methods}

\section{Animals}

Thirty-seven Dunkin-Hartley guinea-pigs weighing 200-300 g were purchased from the animal holding unit at the National University of Singapore. They were given water and chow ad libitum and kept in a 12-h light/dark schedule. Animal work was performed according to the International Guiding Principles for Animal Research [24].

\section{Bacterial strains}

Four H. pylori isolates from gastric biopsies from patients at the Clinic of Gastroenterology at the National University Hospital, Singapore were designated $75,78,79$ and 81 . H. pylori strain gp4 was cultured from an antral biopsy of a previously infected guinea-pig. The bacteria were cultured on chocolate blood agar (CBA; Oxoid) supplemented with defibrinated horse blood (Gibco BRL, Auckland, New Zealand) $10 \%$, in a $\mathrm{CO}_{2} 5 \%$ incubator, at $37^{\circ} \mathrm{C}$ under micro-aerobic conditions. The isolates were subcultured on CBA no more than five times. Before inoculation, the bacteria were cultured in 1-L bottles containing $300 \mathrm{ml}$ of Brain Heart Infusion Broth (BHIB; Gibco BRL), supplemented with yeast extract (Oxoid) $0.4 \%$ and horse serum (Gibco BRL) $10 \%$. The bottles were aerated with $\mathrm{CO}_{2}$ and incubated at $37^{\circ} \mathrm{C}$ with shaking. H. pylori cells were harvested after 3 days by centrifuging broth cultures in $10-\mathrm{ml}$ test tubes ( $3000 \mathrm{~g}$ for $10 \mathrm{~min}$ at $4^{\circ} \mathrm{C}$ ). Supernates were decanted and cell pellets were resuspended by gently shaking in the remaining broth. For the animal groups to be infected with fresh human isolates, bacterial suspensions were mixed into a cocktail containing strains 75 , 78,79 and 81 . The bacterial cell concentrations of all inocula were counted with a haemocytometer.

\section{Challenge and sample collection}

Guinea-pigs were fasted for $24 \mathrm{~h}$ followed by inoculation of either $H$. pylori or sterile BHIB into the oral cavity through a sterile gavage tube. The animals were then fasted for $1 \mathrm{~h}$. The procedure was repeated three times within 1 week. The animals were killed with ether and blood was collected by heart puncture. Blood was not collected from one animal that was infected for 3 weeks; therefore this animal is not included in the serological analyses. Blood samples were kept at room temperature for $1 \mathrm{~h}$ and then at $4^{\circ} \mathrm{C}$ for $24 \mathrm{~h}$; sera were separated and frozen $\left(-20^{\circ} \mathrm{C}\right)$ for serological analyses. Each stomach was removed, including parts of the oesophagus and duodenum, and opened along the major curvature and rinsed with sterile phosphate-buffered saline (PBS, $\mathrm{pH}$ 7.2) and divided along the midline, creating two halves including all regions. One half was fixed in formaldehyde $10 \%$; the other half was again divided into two parts. The mucosal layer of one half was scraped off and suspended in $600 \mu \mathrm{l}$ of PBS; $100 \mu \mathrm{l}$ were cultured under micro-aerobic conditions at $37^{\circ} \mathrm{C}$ on Gab-Camp agar [25]. Gab-Camp agar is a selective medium for $H$. pylori culture consisting of GC Agar Base II (BBL, Cockeysville, USA) 2.5\%, supplemented with Bact Agar, (Difco, Detroit, USA) 0.29\%, cystein$\mathrm{HCl} \mathrm{H}_{2} \mathrm{O}$ (ICN Biomedicals, Aurora, USA) $0.05 \%$, horse blood (Gibco BRL) 8.5\%, horse serum (Gibco BRL) $10 \%$, IsoVitaleX (BBL) $0.35 \%$, vancomycin (ICN Biomedicals) $6.0 \mathrm{mg} / \mathrm{L}$, nalidixic acid (ICN Biomedicals) $20 \mathrm{mg} / \mathrm{L}$, fungizone (Bristol-Meyers Squibb $\mathrm{AB}$, Bromma, Sweden) $2.0 \mathrm{mg} / \mathrm{L}$ and ketokonazole (AB Leo, Helsingborg, Sweden) $3.0 \mathrm{mg} / \mathrm{L}$. The other half of the stomach was divided into the fundic, corpus, antrum and duodenum regions. Each biopsy was inoculated onto one Gab-Camp agar plate. A few stomachs were also inoculated on CBA agar without any antibiotics added. All cultures were incubated at $37^{\circ} \mathrm{C}$ under microaerobic conditions for 4-8 days and bacteria were identified as $H$. pylori by colony morphology and urease, catalase and oxidase tests. Colonies from one region of each stomach were tested by the API-ZYM test (bioMérieux, Marcy-l'Etoile, France).

\section{Experimental protocol}

Group 1 (10 animals) received $2 \mathrm{ml}$ of $\mathrm{NaHCO}_{3}$ $0.2 \mathrm{~mol} / \mathrm{L}$ each followed 5-15 min later by $1 \mathrm{ml}$ of a cocktail of fresh human $H$. pylori isolates containing $10^{8}-10^{10}$ bacteria $/ \mathrm{ml}$. Group 2 (10 animals) received the same treatment, differing from group 1 only in that the animals were fed a suspension of cells of strain gp4. The amount of bacteria was the same as for the first group. Group 3 (nine animals) was also challenged with strain gp4 without pre-treatment with $\mathrm{NaHCO}_{3}$. Group 4, a control group consisting of eight animals, was treated as the first group except that the animals were given $1 \mathrm{ml}$ of sterile BHIB instead of a bacterial suspension. Guinea-pigs were killed either 3 or 7 weeks after the first day of inoculation.

\section{Serology}

Enzyme immunoassay (EIA) and Western blotting were done with acid glycine-extracted $H$. pylori cell surface protein antigen as described by Guruge et al. [26].

Western blotting was used to determine antibodies against specific $H$. pylori surface proteins, as described by Nilsson et al. [27], with minor modifications. Serum samples were diluted 1 in 50 in washing buffer and horseradish peroxidase-labelled goat anti-guinea-pig immunoglobulin (Dako, Glostrup, Denmark) diluted 1 in 600 was used as secondary antibody. 
EIA was used to examine the total IgG levels against H. pylori, as described by Guruge et al. with minor modifications [26]. Wells were coated with $H$. pylori surface proteins [28]; $100-\mu 1$ volumes of the serum samples, diluted 1 in 200 in washing buffer (PBS, Tween $200.05 \%$ ), were added to each well, followed by $100 \mu 1$ of horseradish peroxidase-labelled rabbit anti-guinea-pig immunoglobulins (Dako) diluted 1 in 1000 in washing buffer. Human gammaglobulin was added to positive and negative control wells, followed by rabbit anti-human IgG antibodies (Dako) [26]. The substrate buffer used was $10 \mathrm{mg}$ of 1,2-phenylenediamine diluted in $25 \mathrm{ml}$ of sodium citric acid phosphate $0.1 \mathrm{~mol} / \mathrm{L}$ buffer, pH 5.0 , with $5 \mu \mathrm{l}$ of $\mathrm{H}_{2} \mathrm{O}_{2} 30 \%$. The absorbance at $450 \mathrm{~nm}$ was measured in a spectrophotometer (Labsystem Multiscan Plus, Helsinki, Finland). To eliminate inter-assay variation, background was subtracted and the absorbance was corrected for reference wells by the formula [relative antibody activity $=$ mean absorbance $\times 100 /$ mean absorbance of reference] where mean absorbance is the average of the two wells run on each sample and mean absorbance of reference is the average of the four reference wells.

\section{Histopathology}

Guinea-pig stomachs were fixed in formaldehyde $10 \%$ and embedded in paraffin. Sections, $4 \mu \mathrm{m}$ thick, were prepared and stained with haematoxylin and eosin following standard procedures. As the guinea-pig stomach has only a small cardia region and as the fundic region could not be distinguished histologically from the corpus region, only two areas of the stomach were examined: the corpus and canalis regions. The inflammation was graded from 0 to 3 'blindly' by two separate examiners by light microscopy. The inflammation in a stomach region was graded 0 when no inflammatory cells were observed in the corpus or canalis mucosa. If small groups of inflammatory cells were seen adjacent to the lamina muscularis mucosae, the inflammation was graded 1 . If the number of cells in the inflammatory infiltrates was more intense, with inflammatory cells spreading up through the mucosal layer and if these infiltrates were noted in several locations, the inflammation was graded 2 . The inflammation was graded 3 if it was severe, with numerous heavy inflammatory infiltrates spreading through the whole mucosal thickness and with formation of lymphoid follicles.

Duodenum samples were not analysed because a basal infiltration of inflammatory cells was present.

\section{Statistical analysis}

The unpaired, one-tailed Mann-Whitney $U$ test was used for the inflammation distributions and EIA results. The level of significance selected was $\mathrm{p}<0.05$.

\section{Results}

\section{Culture}

H. pylori was recovered from the stomachs of $22(76 \%)$ of 29 challenged guinea-pigs (Table 1). Of seven challenged animals from which $H$. pylori could not be recovered, two were seronegative in Western blotting and exhibited no gastritis, four exhibited mild to severe gastritis of which three were seropositive in Western blotting and one animal showed no gastritis but was seropositive in Western blotting. In the two groups infected with the gp4 strain, bacteria were recovered from $16(84 \%)$ of 19 animals, while in the group infected with four fresh human isolates six $(60 \%)$ of 10 were culture positive. H. pylori was not cultured from any uninfected control animal. Bacteria were recovered on both Gab-Camp and CBA agar plates, but the former was a more reliable medium. Inoculation of gastric biopsy samples was a more successful method of recovering $H$. pylori than was inoculation of mucosal tissue suspended in PBS.

\section{Serology}

All culture-positive guinea-pigs showed distinct immune responses against 19-, 25.5-26- and 29.5-30$\mathrm{kDa} H$. pylori surface proteins in Western blotting at 3 and 7 weeks after infection (Fig. 1). To a lesser degree, immune responses towards 28-, 35-, 54-, 74- and 85$\mathrm{kDa}$ proteins were detected. There was no difference between the groups with regard to the protein bands immunostained in Western blotting. In total, 25 of 29 H. pylori-challenged guinea-pigs exhibited immunostained protein bands in Western blotting, compared with none of eight uninfected control animals. Serum could not be analysed from one culture-positive animal infected for 3 weeks. The mean EIA relative antibody activity was higher $(\mathrm{p}<0.05)$ in the $H$. pylorichallenged groups than in the control group after 3 and 7 weeks (Fig. 2). No difference in EIA titre was found between the three $H$. pylori-challenged groups.

\section{Histopathology}

All culture-positive animals showed gastritis - two with mild, four with moderate and 16 animals with severe gastritis. In the control group of eight animals, one had mild gastritis while the other seven had no

Table 1. Culture results

\begin{tabular}{lcc}
\hline & \multicolumn{2}{c}{ Culture-positive animals/total } \\
\cline { 2 - 3 } Group no. $^{*}$ & 3 weeks & 7 weeks \\
\hline 1 & $3 / 3$ & $3 / 7$ \\
2 & $3 / 3$ & $5 / 7$ \\
3 & $2 / 3$ & $6 / 6$ \\
4 & $0 / 3$ & $0 / 5$ \\
\hline
\end{tabular}

*Group 1, infected with fresh isolates of $H$. pylori; group 2, infected with strain gp4; group 3, infected with strain gp4, not pretreated with bicarbonate; group 4 , uninfected control animals. 


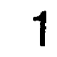

37

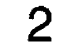

\section{$\mathrm{kDa}$}
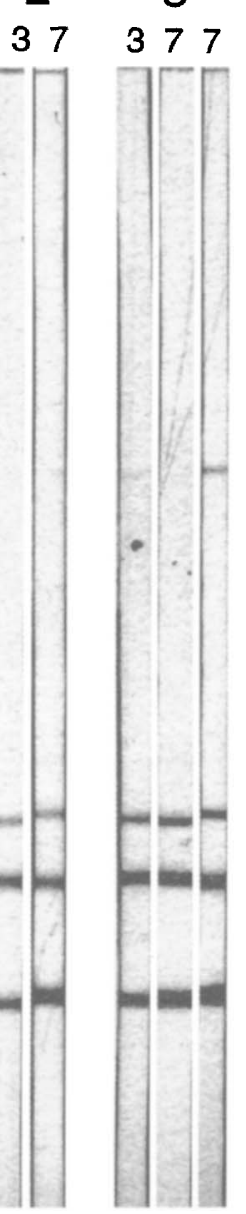
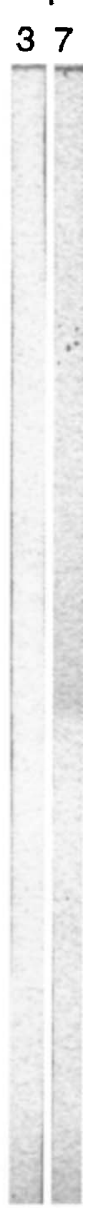

Fig. 1. Western blotting results. Groups 1-3, infected animals 3 and 7 weeks after inoculation; group 4, uninfected control.

gastritis (Fig. 3). The level of gastritis in the groups challenged with $H$. pylori was significantly higher than in the control group $(\mathrm{p}<0.001)$. The inflammatory cell response consisted of both polymorphonuclear leucocytes and lymphocytes, after 3 and 7 weeks, with inflammatory cells infiltrating the whole mucosa. Intraepithelial granulocytes and crypt abscesses were found in all stomachs with moderate to severe intensity of the gastritis reaction. Lymphoid follicles were often formed in the stomachs of infected animals. Generally, gastritis was more pronounced in the canalis region than in the corpus area and usually the degree of inflammation in the corpus was higher in the mucosal region adjacent to the canalis than in other regions. The infected animals showed dilated capillaries in the inflamed gastric mucosa and sometimes exhibited erosions as well as increased mucin production.

\section{Discussion}

In recent years rapid progress has been made in $H$. pylori research pertaining to the development of new animal models of infection. Preferably, an animal closely resembling man in stomach anatomy and

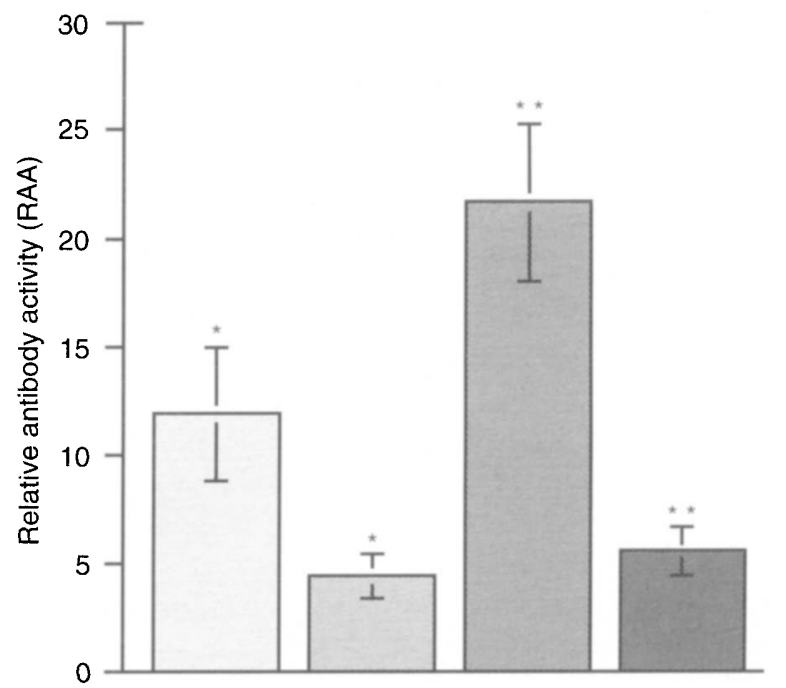

Fig. 2. Relative antibody activity (RAA) in serum towards glycine-extracted $H$. pylori antigens in infected and uninfected guinea-pigs, detected in EIA. Differences are seen between the infected and the uninfected animals at 3 and 7 weeks after challenge ( ${ }^{*}$ and ${ }^{* *} \mathrm{p}<0.05$; Mann Whitney $U$ test). Bars represents SEM of the analysed serum samples. Number of samples analysed in each group: infected 3 weeks ( $\square$ ) - eight samples; control 3 weeks (圈) - three samples; infected 7 weeks (四) - 20 samples; control 7 weeks - five samples.

physiology should be used for this purpose. Unlike other small laboratory animals, the epithelium of the fundic region of the guinea-pig stomach is covered by a cylindrical glandular epithelium and not a squamous epithelium. The fact that guinea-pigs, like man, produce interleukin- 8 indicates that guinea-pigs are suitable for studies of local inflammatory response in the stomach, and the effect of vitamin $\mathrm{C}$ intake on $H$. pylori-related diseases can readily be studied in guineapigs as they require this as a dietary supplement.

The present study found that guinea-pigs can sustain H. pylori infection for at least 7 weeks and further investigations will determine whether the infection exhibits a long-term persistence, as in man. Feeding the animals bicarbonate to raise the $\mathrm{pH}$ in the stomach before inoculation is not essential for the ability of $H$. pylori to colonise the guinea-pig stomach. However, in a $\mathrm{T}_{84}$ human intestinal cell monolayer culture system, H. pylori adhesion was found to be $\mathrm{pH}$ dependent [29]. In the present study, the recovery rate of $H$. pylori from challenged animals was $76 \%$. Culture of H. pylori from stomach biopsy samples is the most certain proof of colonisation and ideally the model should be optimised to ensure recovery from all challenged animals. $H$. pylori could not be recovered from any of the unchallenged control animals, indicating that there was no transmission of the infection between animals in different cages.

The serological response analysed by Western blotting demonstrated which proteins gave an early immune response. The 19-, 25.5-26- and 29.5-30-kDa pro- 

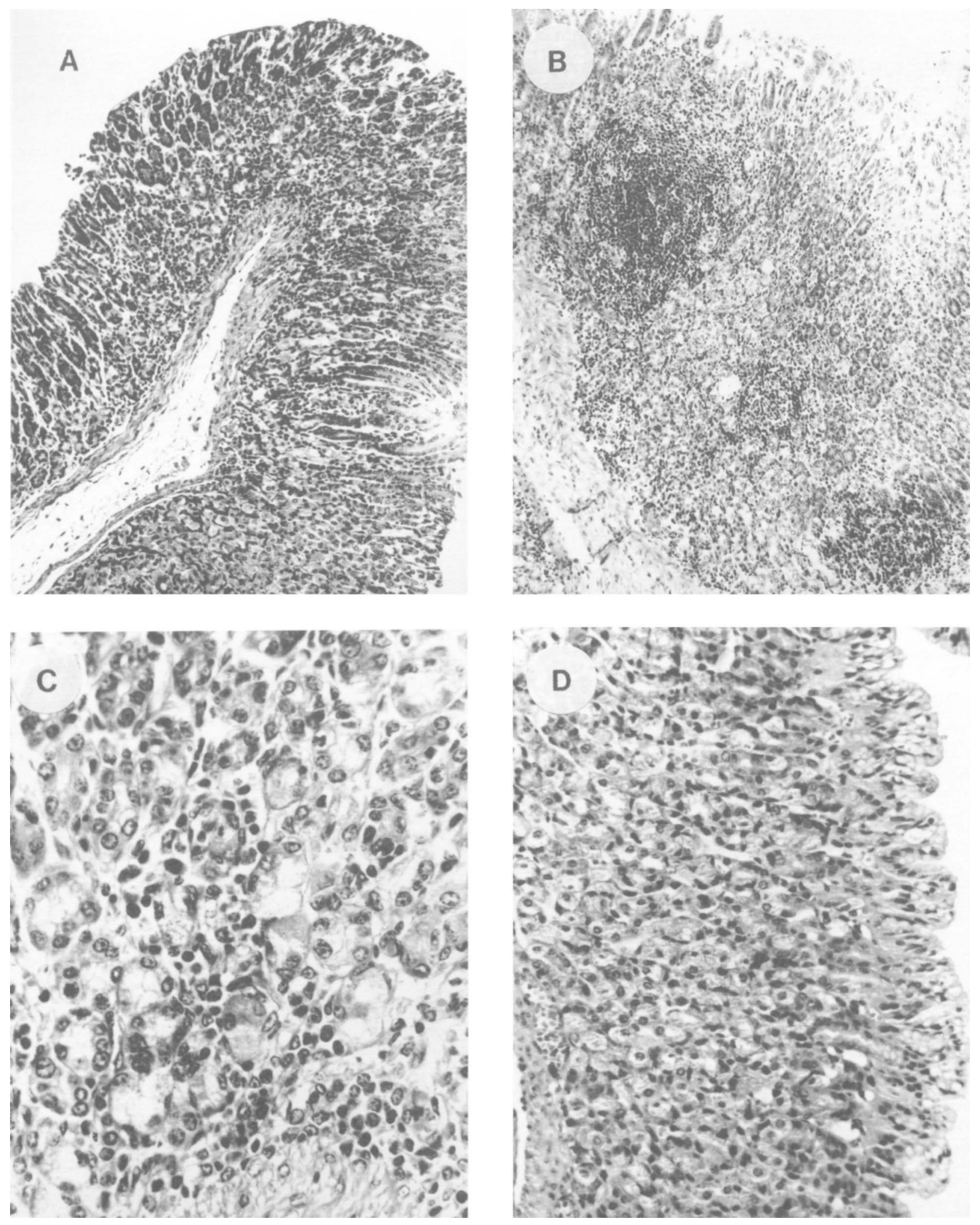

Fig. 3. Histopathology of corpus region of guinea-pig stomachs ( $H$ and E). (A) Inflammation grade 3: diffuse infiltration of inflammatory cells throughout the mucosa $(\times 45)$. (B) Inflammation grade 3: lymphoid follicle formation and erosion of gastric epithelium with elevated levels of mucin production $(\times 45)$. (C) Inflammation grade 3 : higher magnification of inflammatory cell infiltration of the mucosa $(\times 250)$. (D) Inflammation grade 0: no infiammatory cells present in the mucosa $(\times 140)$.

teins probably represent a species-specific outermembrane protein, a species-specific protein described by O'Toole et al. and the low mol.wt subunit of urease, respectively [30-32].
These proteins may be candidate antigens for an experimental vaccine. Western blotting provides the opportunity to monitor the immune response in infected animals without killing them. The uninfected 
control animals had no immune response against $H$. pylori, as seen in Western blotting, indicating that healthy guinea-pigs possess no natural cross-reacting antibodies against $H$. pylori. This makes Western blotting a method with high specificity to determine whether or not animals are infected. EIA showed significantly higher antibody titres against $H$. pylori after 3 weeks than in control animals and the antibody titres were still elevated 7 weeks after infection, which correlates well with the results in Western blotting. Two culture-negative animals challenged with fresh human isolates and killed 7 weeks after infection showed no serological immune response and no gastric inflammation. The fact that these animals were negative in Western blotting suggests that the challenge per se will not cause a long-lasting elevation of antibody titres - at least not in all cases. The other five challenged culture-negative animals could represent individuals that were infected but the culture from the biopsy was unsuccessful, individuals that were previously infected but the infection had healed or individuals that were never infected but the inoculum in itself caused a lasting gastritis and elevation of antibody titres. However, the latter explanation is not likely for the animals killed 7 weeks after inoculation, as at least the gastritis should have disappeared by then.

In light microscopy, the histopathological picture was very similar to that found in human $H$. pylori infection. A transmucosal inflammation with crypt abscesses, erosions and formation of lymphoid follicles was often found. Compared with the mouse model, the inflammatory cell response was much more pronounced, not only demarcated to the lamina muscularis mucosae, but also more extensively distributed [33]. Thus a severe gastritis was observed in most infected animals and a control group of uninfected animals showed no or very low levels of inflammation. These results suggest that the guinea-pig represents a good new model to study $H$. pyloriinduced type $\mathrm{B}$ gastritis and associated diseases.

We thank Hua Jiesong at the Department of Microbiology, National University of Singapore, for supplying the bacterial strains and Anna Jonsson and Ingrid Nilsson for their technical assistance. This study was done as a part of the Lund-Singapore student exchange programme and was supported by grants from the Swedish Medical Research Council (project 16X 04723), the National University of Singapore (A/C No $16412 / 16412$ ) and the Medical Faculty in Lund University

\section{References}

1. Marshall BJ, Warren JR. Unidentified curved bacilli in the stomach of patients with gastritis and peptic ulceration. Lancet 1984; 1: $1311-1315$.

2. NIH Consensus Development Panel on Helicobacter pylori in Peptic Ulcer Disease. Helicobacter pylori in peptic ulcer disease. JAMA 1994; 272: 65-69.

3. Parsonnet J, Friedman GD, Vandersteen DP et al. Helicobacter pylori infection and the risk of gastric carcinoma. $N$ Engl $J$ Med 1991; 325: 1127-1131.

4. Forman D, Newell DG, Fullerton F et al. Association between infection with Helicobacter pylori and risk of gastric cancer: evidence from a prospective investigation. $B M J 1991 ; 302$ : 1302-1305.

5. Marchetti M, Aricó B, Burroni D, Figura N, Rappuoli R, Ghiara P. Development of a mouse model of Helicobacter pylori infection that mimics human disease. Science 1995; 267: 1655-1658.

6. Krakowka S, Eaton KA, Rings DM, Morgan DR. Gastritis induced by Helicobacter pylori in gnotobiotic piglets. Rev Infect Dis 1991; 13 Suppl 18: 681-685.

7. Engstrand L, Gustavsson S, Jörgensen A, Schwan A, Scheynius A. Inoculation of barrier-born pigs with Helicobacter pylori: a useful animal model for gastritis type B. Infect Immun 1990; 58: $1763-1768$

8. Fukuda Y, Yamamoto I, Tonokatsu Y, Tamura K, Shimoyama T. Inoculation of rhesus monkeys with human Helicobacter pylori: a long-term investigation on gastric mucosa by endoscopy. Diagn Endosc 1992; 4: 19-30.

9. Radin MJ, Eaton KA, Krakowka S et al. Helicobacter pylori gastric infection in gnotobiotic beagle dogs. Infect Immun 1990; 58: 2606-2612.

10. Karita M, Kouchiyama T, Okita K, Nakazawa T. New small animal model for human gastric Helicobacter pylori infection: success in both nude and euthymic mice. Am $J$ Gastroenterol 1991; 86: 1596-1603

11. Fox JG, Correa P, Taylor NS et al. Helicobacter mustelaeassociated gastritis in ferrets. An animal model of Helicobacter pylori gastritis in humans. Gastroenterology 1990; 99: 352-361.

12. Fox JG, Lee A, Otto G, Taylor NS, Murphy JC. Helicobacter felis gastritis in gnotobiotic rats: an animal model of Helicobacter pylori gastritis. Infect Immun 1991; 59: 785-791.

13. Aleljung $\mathrm{P}$, Nilsson $\mathrm{H}-\mathrm{O}$, Wang $\mathrm{X}$ et al. Gastrointestinal colonisation of $\mathrm{Balb} / \mathrm{cA}$ mice by Helicobacter pylori monitored by heparin magnetic separation. FEMS Immunol Med Microbiol 1996; 13: 303-309.

14. Blanchard TG, Nedrud JG, Czinn SJ. Development of a rat model of $H$. pylori infection and disease to study the role of H. pylori in gastric cancer incidence. Gut 1996; 39 Suppl 2: A76.

15. Sawada $\mathrm{Y}$, Sashio $\mathrm{H}$, Hida $\mathrm{N}$ et al. The experimental model with $H$. pylori infection in mongolian gerbils. Gut 1996; 39 Suppl 2: A74.

16. Matsumoto S, Washizuka Y, Matsumoto $\mathrm{Y}$ et al. Induction of ulceration and severe gastritis in Mongolian gerbil by Helicobacter pylori infection. J. Med Microbiol 1997; 46: $391-397$.

17. Hirayama F, Takagi S, Yokoyama Y, Iwao E, Ikeda Y. Establishment of gastric Helicobacter pylori infection in Mongolian gerbils. J Gastroenterol 1996; 31 Suppl 9: 24-28.

18. National Research Council. Nutrient requirements of laboratory animals, 4th edn. Washington, DC, National Academy Press. 1995: $103-124$.

19. Breazile JE, Brown EM. Anatomy. In: Wagner JE, Manning PJ (eds) The biology of the guinea pig. New York, Academic Press. 1976: 53-62.

20. Navia JM, Hunt CE. Nutrition, nutritional diseases and nutrition research applications. In: Wagner JE, Manning PJ (eds) The biology of the guinea pig. New York, Academic Press. 1976: 235-267.

21. Ediger RD. Care and management. In: Wagner JE, Manning PJ (eds) The biology of the guinea pig. New York, Academic Press. 1976: 5-12.

22. Yoshimura T, Johnson DG. cDna cloning and expression of guinea pig neutrophil attractant protein-1 (NAP-1). NAP-1 is highly conserved in guinea pig. J Immunol 1993; 151: $6225-6236$.

23. Sturegård $E$, Sjunnesson $H$, Willén $R$, Aleljung $P$, Ho $B$, Wadström T. Severe gastritis in Helicobacter pylori-infected guinea pigs. Gut 1997; 41 Suppl 1: A118.

24. International Guiding Principles for Animal Research. WHO Chronicle 1985; 39: 51-56.

25. Soltez V, Schalén C, Mårdh PA. New selective medium for Campylobacter pylori. Proceedings of the Fourth International Workshop on Campylobacter infections, University of Gothenburg, Gothenburg, Sweden, 1988: 433-436.

26. Guruge JL, Schalén C, Nilsson I et al. Detection of antibodies to Helicobacter pylori cell surface antigens. Scand J Infect Dis 1990; 22: 457-465. 
27. Nilsson I, Ljungh $\AA$, Aleljung P, Wadström T. Immunoblot assay for serodiagnosis of Helicobacter pylori infections. $J$ Clin Microbiol 1997; 35: 427-432.

28. Lelwala-Guruge J, Nilsson I, Ljungh $\AA$, Wadström T. Cell surface proteins of Helicobacter pylori as antigens in an ELISA and a comparison with three commercial ELISA. Scand $J$ Infect Dis 1992; 24: 457-465.

29. Corthésy-Theulaz I, Porta N, Pringault E et al. Adhesion of Helicobacter pylori to polarized $\mathrm{T}_{84}$ human intestinal cell monolayers is $\mathrm{pH}$ dependent. Infect Immun 1996; 64: 3827-3832.

30. Drouet EB, Denoyel GA, Boude M, Wallano E, Andujar M, de Montclos HP. Characterization of an immunoreactive species- specific 19-kilodalton outer membrane protein from Helicobacter pylori by using a monoclonal antibody. J Clin Microbiol 1991; 29: $1620-1624$.

31. O'Toole PW, Logan SM, Kostrynska M, Wadström T, Trust TJ Isolation and biochemical and molecular analyses of a speciesspecific protein antigen from the gastric pathogen Helicobacter pylori. J Bacteriol 1991; 173: 505-513.

32. Turbett GR, Høj PB, Horne R, Mee BJ. Purification and characterization of the urease enzymes of Helicobacter species from humans and animals. Infect Immun 1992; 60: 5259-5266.

33. Wang $\mathrm{X}$, Sturegård $\mathrm{E}$, Rupar $\mathrm{R}$ et al. Infection of $\mathrm{BALB} / \mathrm{c} A$ mice by spiral and coccoid forms of Helicobacter pylori. $J$ Med Microbiol 1997; 46: 657-663. 